\title{
Improvement of photosynthesis in rice (Oryza sativa L.) by inserting the C4 pathway
}

\author{
Shanta Karki ${ }^{1 *}$, Govinda Rizal ${ }^{1}$ and William Paul Quick ${ }^{1,2}$
}

\begin{abstract}
To boost food production for a rapidly growing global population, crop yields must significantly increase. One of the avenues being recently explored is the improvement of photosynthetic capacity by installing the C4 photosynthetic pathway into C3 crops like rice to drastically increase their yield. Crops with an enhanced photosynthetic mechanism would better utilize the solar radiation that can be translated into yield. This subsequently will help in producing more grain yield, reduce water loss and increase nitrogen use efficiency especially in hot and dry environments. This review provides a summary of the factors that need to be modified in rice so that the C4 pathway can be introduced successfully. It also discusses the differences between the C 3 and C4 photosynthetic pathways in terms of anatomy, biochemistry and genetics.
\end{abstract}

Keywords: Bundle sheath; Chloroplast; Mesophyll; Photorespiration; Photosynthesis

\section{Review}

\section{Introduction}

To provide adequate food and nutrition to the global population that is expected to reach 9 billion by 2050 (www.unpopulation.org), rice yields need to increase by at least 60\% (FAO 2009). Rice is the staple food of over half of the world's population and this rice consuming population is increasing at the rate of $1.098 \%$ per annum (http://esa.un.org/wpp/Excel-Data/population.htm). Escalating population means more demand for food, water and land at a time when the natural resource base for agriculture is being degraded because large areas of farmland are being diverted from food production to industrialization and bio-fuel production. An unpredictable climate change is threatening to further reduce agriculturally viable land due to more instances of drought and flood (http://www. fao.org/docrep/017/aq191e/aq191e.pdf). As a growing population and global climate change place increasing pressure on the world's food supply, it is essential that we continue to improve crop performance in terms of grain productivity to keep pace with population growth. The increase in crop productivity conferred by the plant types created during green revolution period supported the

\footnotetext{
* Correspondence: s.karki@irri.org

${ }^{1}$ C4 Rice Center, International Rice Research Institute, Los Banos, Laguna, Philippines

Full list of author information is available at the end of the article
}

population boom following the two world wars. Since then, despite the use of improved varieties and advanced technologies, the yield potential of present day rice cultivars has improved just a little indicating that these varieties have hit a yield ceiling (Akita 1994). Recently an attempt is underway to increase the rice yield potential by engineering an efficient $\mathrm{C} 4$ type photosynthesis into rice (Kajala et al. 2011). For this, a set of genes which regulate leaf anatomy and biochemical processes have to be inserted into rice and expressed in an appropriate manner which is currently not possible solely by conventional plant breeding techniques. Therefore, genetic engineering to improve the photosynthetic pathway of rice would provide sufficient opportunity to enhance the actual grain productivity as well as the yield potential. Genetic engineering provides an efficient and precise breeding tool in which only the genes of interest can be introduced even from distantly related species.

In $\mathrm{C} 3$ plants like rice, $\mathrm{CO}_{2}$ is assimilated into a 3-carbon compound by the photosynthetic enzyme ribulose-1, 5bisphosphate carboxylase oxygenase (Rubisco). As the name indicates, Rubisco also catalyzes oxidation of ribulose-1, 5-bisphosphate (RuBP) in a wasteful process known as photorespiration which can incur a loss of upto $25 \%$ of previously fixed carbon (Sage 2004). At temperature above $30^{\circ} \mathrm{C}$ which is typical of tropical rice growing areas of the world, rate of oxygenation increases substantially and this 
considerably reduces the photosynthetic efficiency of $\mathrm{C} 3$ plants by upto 40\% (Ehleringer and Monson 1993). Thus, photosynthesis of rice in the tropics and warm temperate regions becomes inefficient. The $\mathrm{C} 4$ plants which have $\mathrm{CO}_{2}$ concentrating mechanism within their leaves have very much reduced levels of photorespiration and thus have evolved to thrive in hot, arid environments and offer valuable insights for crop improvement strategies. Rice with a $\mathrm{C} 4$ photosynthesis mechanism would have increased photosynthetic efficiency while using scarce resources such as land, water, and fertilizer specifically nitrogen more effectively (Hibberd et al. 2008). Because it will perform well under high temperature as well as require less water and nitrogen, $\mathrm{C} 4$ rice would confer benefits on different types of rice ecosystems including the marginal lands.

C4 type photosynthesis is one of the three types of biochemical mechanisms adopted by plants to fix atmospheric $\mathrm{CO}_{2}$, others being $\mathrm{C} 3$ and Crassulacean acid metabolism (CAM) pathways. C4 photosynthesis has evolved more than 66 times independently (Sage et al. 2012) at least in 19 families during angiosperm evolution from C3 ancestors (Muhaidat et al. 2007) and it entails alternations of cellular structures, biochemistry and hence the development of leaves. This highly specialized form of photosynthesis essentially has developed a $\mathrm{CO}_{2}$ concentrating mechanism around the Rubisco enzyme thus eliminating the oxygenase function of Rubisco thereby reducing the wastage of energy due to photorespiration (Douce and Heldt 2000). Rubisco from C4 species is more efficient than from C3 species in terms of carboxylation (Kubien et al. 2008). The other associated benefits of the $\mathrm{C} 4$ system include higher water use efficiency because steeper concentration gradient for $\mathrm{CO}_{2}$ diffusion can be maintained through partly closed stomata, higher radiation use efficiency as $\mathrm{C} 4$ photosynthesis efficiency does not get saturated at high light intensity (Rizal et al. 2012) and higher nitrogen use efficiencies because it will require less Rubisco and hence less nitrogen.

C4 plants are potentially more productive at higher temperatures typically experienced by rice. To take advantage of this more efficient photosynthetic system at a time when the population and food prices are soaring, there are efforts towards inserting the C4 mechanism such as that found in maize into rice (Rizal et al. 2012). This novel approach to modify the photosynthesis system of rice is a challenging and long term endeavor because the C4 pathway is very complex and many factors controlling the mechanism are still unknown. Therefore, it requires ingenuity and expertise of scientists involved in diverse disciplines such as genetic engineering, biochemistry, bioinformatics, molecular biology, photosynthesis, systems biology, physiology, plant breeding, metabolomics, etc. For the same, the $\mathrm{C} 4$ rice consortium was conceptualized and established which began the practical work of $\mathrm{C} 4$ rice engineering since 2009 (http://photosynthome.irri. org/C4rice/). This review provides an update on the requirements to develop $\mathrm{C} 4$ rice and progress made in the field of genetic engineering. Based on the study of the evolution of C4 from C3 species and the associated changes, the following modifications are essential to establish a functional $\mathrm{C} 4$ photosynthetic pathway in rice.

\section{Increase the number and size of chloroplasts in bundle sheath cells of rice}

In rice more than $90 \%$ of the total chloroplasts are located in mesophyll cells (MCs) within the leaf (Yoshimura et al. 2004); whereas, in C4 plants both MCs and bundle sheath cells (BSCs) possess equal numbers of chloroplasts (Figure 1A and B). This is because in C3 plants, the entire process of photosynthesis takes place in $\mathrm{MC}$, but in $\mathrm{C} 4$ plants the process of photosynthesis is compartmentalized into $\mathrm{MC}$ and $\mathrm{BSC}$. The $\mathrm{MCs}$ perform the first $\mathrm{CO}_{2}$ fixation in which 4-carbon compound called oxaloacetate is formed and this is converted to $\mathrm{C} 4$ acids such as malate which get transported into BSCs thereby enabling efficient assimilation of $\mathrm{CO}_{2}$ into carbohydrates by the Calvin cycle in BSCs. Therefore, unlike in C3 plants, the BSCs of C4 plants have photosynthetic functions such as the decarboxylation of the $\mathrm{C} 4$ compound and the process of the Calvin cycle. To perform these processes, the BSCs in C4 plants are enlarged and have more chloroplasts, thereby making the BSCs more pronounced and photosynthetically active. The BSCs in C3 species function to balance hydraulic pressure, prevent entry of air from intercellular spaces to the xylem, provide a reservoir of water to buffer losses due to transpiration, allow entry and dispersion of higher intensity of light that hits the veins into the leaf (Nikolopoulos et al. 2002). Additional functions of BSCs of C3 plants include transport of nitrogen, sulphur, carbohydrate and role in signaling pathway which has been extensively reviewed in (Leegood 2008). In C4 species, BSCs and MCs cooperate in a two-step version of the photosynthesis. As a result, to ensure a direct contact between BSCs and MCs, C4 plants possess a special kind of leaf anatomy accompanied by proliferation of chloroplasts in BSCs. To introduce the C4 pathway into rice, more photosynthetic chloroplasts are required in the BSCs than rice has now. This could be done by over expressing the genetic elements that are necessary for the chloroplast development such as Golden2-like (GLK) genes in a cell specific manner by using $\mathrm{C} 4$ gene promoters such as phosphoenolpyruvate carboxylase (PEPC) of Zea mays for MC specific expression and phosphoenolpyruvate carboxykinase (PCK) promoter of Zoysia japonica for BSC specific expression in rice leaves (Matsuoka et al. 1994; Nomura et al. 2005). 

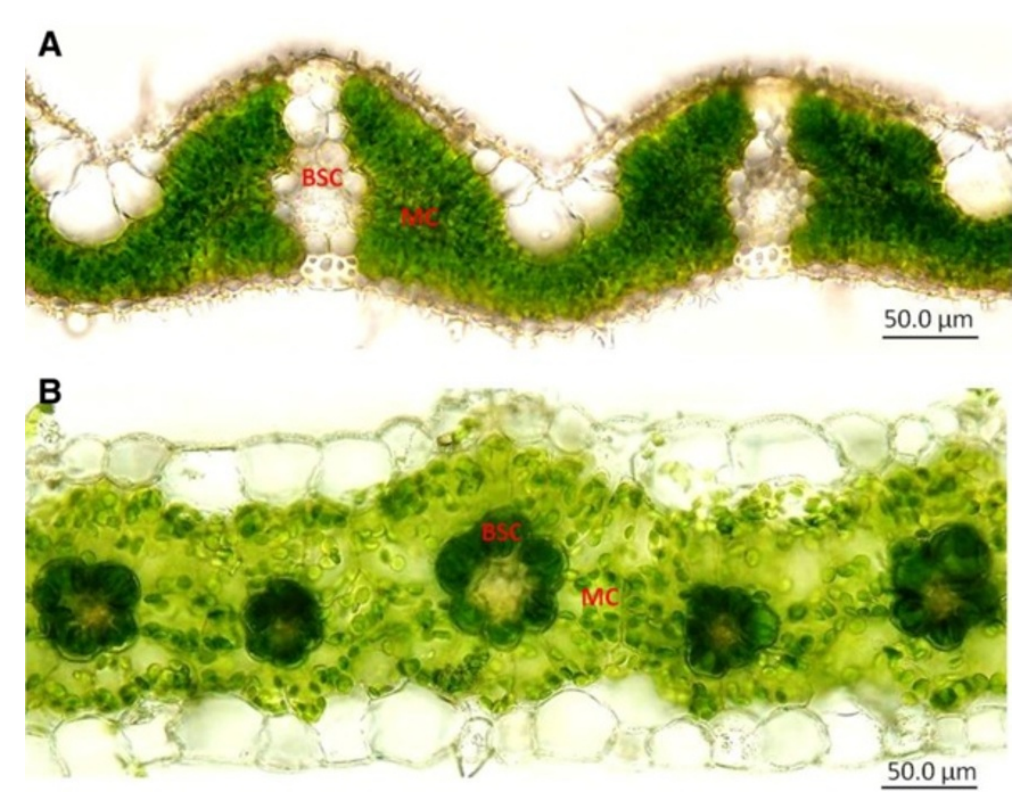

Figure 1 Anatomical differences between C3 and C4 leaves. (A) C3 (Oryza sativa L., rice variety IR64) and (B) C4 (Setaria viridis) leaf. Mesophyll cell (MC) of rice is filled with chloroplasts which is more than $90 \%$ of the total chloroplasts, whereas, the bundle sheath cells (BSC) have very few number of chloroplasts which account for less than 10\% of the total chloroplasts in the rice leaves. In C4 leaf, chloroplasts are localized in BSC as well as in MC.

Golden2-like (GLK) gene family members encode nuclear transcription factors that have been implicated to regulate chloroplast development in Arabidopsis, Zea mays, and the moss Physcomitrella patens (Rossini et al. 2001). In each of these species, GLK genes exist as a homologous pair named as GLK1 and GLK2 (Waters et al. 2009). In moss and Arabidopsis the GLK genes are redundant and functionally equivalent whereas in maize and sorghum GLK genes act in a cell-type-specific manner to direct the development of dimorphic chloroplasts (Waters et al. 2008; Wang et al. 2013a). In maize, Golden2 (G2) and its homologue ZmGLK1 transcripts accumulate primarily in BS and $M$ cells, respectively, suggesting a specific role for each gene regulating the dimorphic chloroplast differentiation (Wang et al. 2013a).

\section{Reduce the vein spacing thereby increasing the vein density in the leaf}

In C3 species, photosynthesis takes place in the MCs. High numbers of MCs between the consecutive veins (Figure 1A) pushes the veins far from each other thus increasing the vein spacing or reducing the vein density. In rice leaves there are less than 6 veins per mm (Figure 2A), Setaria viridis and sorghum (both are typical C4 species) have more than 7 veins per $\mathrm{mm}$ (Figure $2 \mathrm{~B}$ and $\mathrm{C}$ ). $\mathrm{C} 4$ leaves on average have $2 \mathrm{MCs}$ between the veins (Figure 1B). The higher vein density in the leaves of $\mathrm{C} 4$ plants leads to a nearly one-to-one ratio of the volumes of
$\mathrm{M}$ and BS tissues. The internal anatomy of a C4 leaf is often composed of a repeating pattern of vein-BS-M-MBS-vein. BSCs surrounded by MCs form a wreath-like structure; this type of leaf anatomy was termed as "Kranz anatomy" by the German botanist G. Haberlandt. C4 BSCs have dense cytoplasm and are filled with large numbers of chloroplasts (Figure 1B). For the efficient functioning of the C4 pathway, a close contact between M and BS cells is indispensable and these are tightly interconnected to each other with large numbers of plasmodesmata Dengler and (Nelson 1999). Kranz anatomy is found with little variation in nearly all monocotyledonous and dicotyledonous lineages that use the two-cell mode of $\mathrm{C} 4$ photosynthetic pathway. Studies on leaf anatomy and morphology have revealed several genes responsible for growth, development or deformities of cells in leaves. A gene ACAULIS1 was responsible for elongation of leaf cells (Tsukaya et al. 1993). Mutation in CURLEY LEAF (CLF) gene produced curled leaves in Arabidopsis (Kim et al. 1998). Increase in free vein ending, open venation pattern and rounded leaf structure were caused by rotunda 1 (RON1) (Robles et al. 2010). Mutation in the Scarecrow gene in maize showed increase in number of BSCs, unusual differentiation of BS chloroplast, decrease in minor veins and alteration in vein density (Slewinski et al. 2012). These studies related to the abnormal vein patterning caused by mutation of particular genes provide some clue as to how Kranz anatomy is regulated and suggest involvement of multiple pathways 


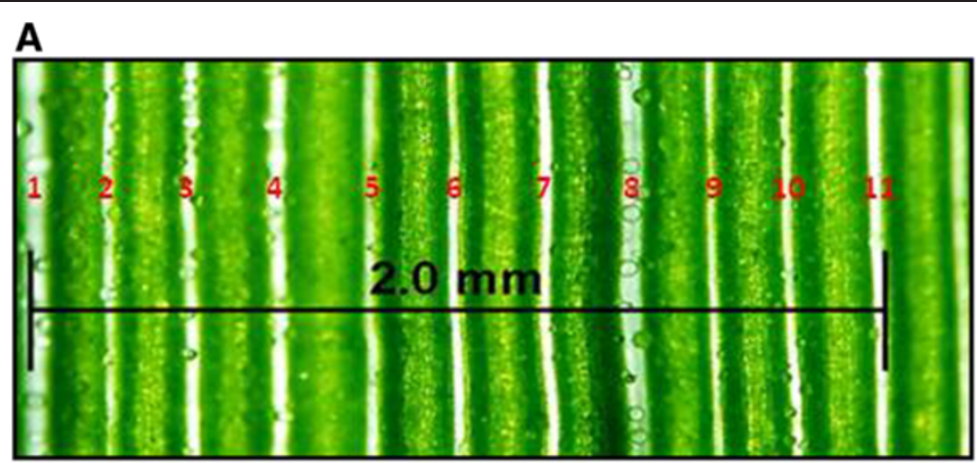

B

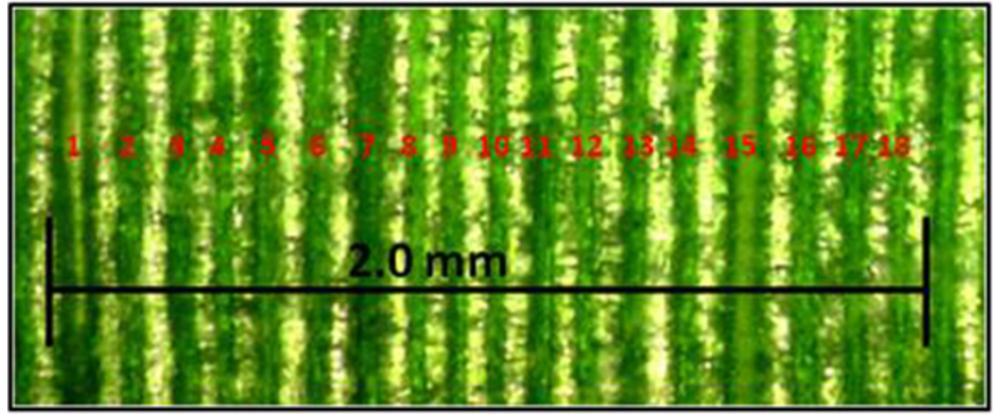

C

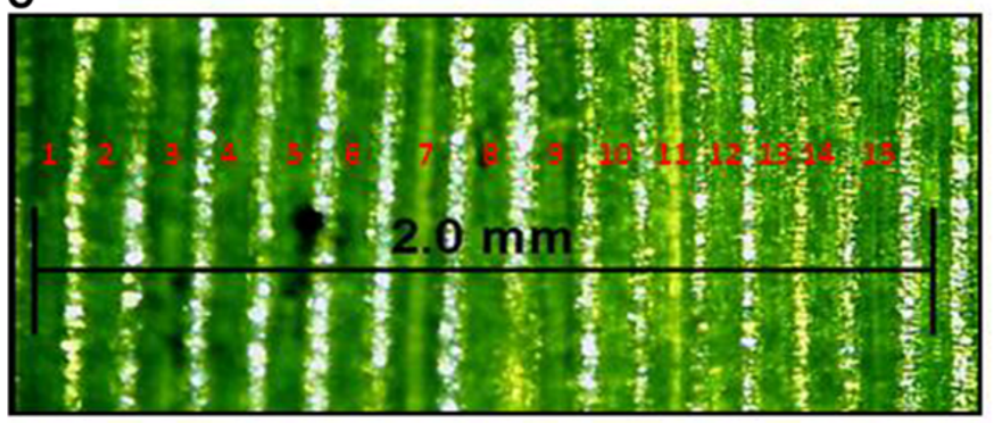

Figure 2 Variation in leaf vein density between C3 and C4 plants. Vein density of (A) C3 (Oryza sativa L., rice variety IR64), (B) C4 (Setaria viridis) and (C) C4 (Sorghum bicolor) leaf sections. Rice has low vein density compared to the C4 plants like S. viridis and sorghum.

in development of the Kranz pattern. The SCARECROW/ SHORTROOT regulatory network has been determined to be one of the important components required for Kranz anatomy patterning because the leaves of C3 plants with mutated Scarecrow gene was normal, while in the C4 plants mutation in the same gene damaged the Kranz anatomy (Slewinski et al. 2012; Wang et al. 2013b). Recently, it has been shown that introduction of maize chromosomes into oat could increase the BSC size and reduce vein spacing in $\mathrm{C} 3$ oat leaves demonstrating that the anatomy of C3 leaf can be modified (Tolley et al. 2012). Moreover, a large effort has been put to screen sorghum (C4) mutants with increased vein spacing and rice $(\mathrm{C} 3)$ mutants with reduced vein spacing so that the genes controlling vein spacing trait can be identified (Rizal et al. 2012).
The activity of the Calvin cycle should be significantly reduced in MC and greatly enhanced in the BSC of rice C4 photosynthesis is characterized by a biochemical $\mathrm{CO}_{2}$ pumping mechanism that elevates the concentration of $\mathrm{CO}_{2}$ at the site of Rubisco. A high level of $\mathrm{CO}_{2}$ around Rubisco reduces the rate of photorespiration and increases net $\mathrm{CO}_{2}$ assimilation leading to highly efficient photosynthesis Weber and von (Caemmerer 2010). To achieve this, the $\mathrm{CO}_{2}$ assimilation in $\mathrm{C} 4$ is distributed over two cell types, the MCs and BSCs (Figure 3). Therefore, C4 carbon fixation depends on cell-specific gene expression and localization. The neighboring photosynthetically active $\mathrm{BS}$ and $\mathrm{M}$ cells interact to eliminate Rubisco-catalyzed $\mathrm{O}_{2}$ fixation. In two-celled type $\mathrm{C} 4$ plants, $\mathrm{CO}_{2}$ is at first fixed into the $\mathrm{C} 4$ acid named as oxaloacetate in $\mathrm{MCs}$ by an $\mathrm{O}_{2}$-insensitive 


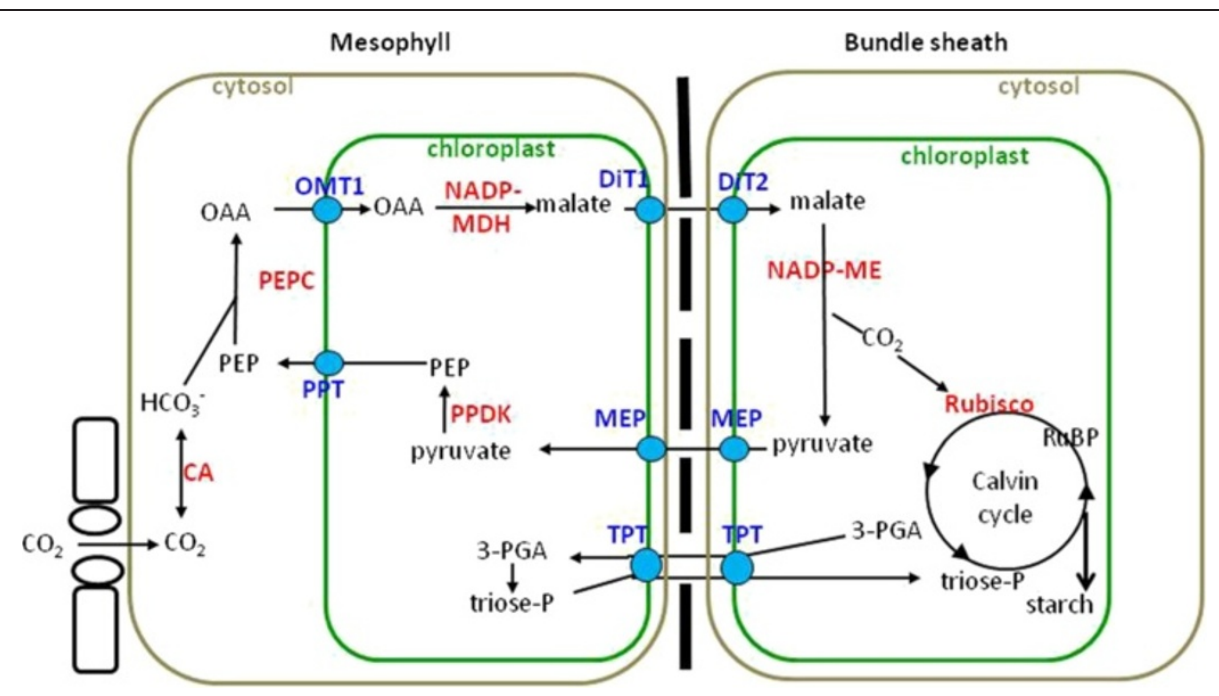

Figure 3 Simplified biochemical pathway of NADP-ME subtype of C4 photosynthesis that is being genetically engineered into indica rice variety by the $\mathrm{C} 4$ rice consortium. PEPC does the first carboxylation in the $\mathrm{MC}$ producing oxaloacetate which is further converted to malate by $\mathrm{MDH}$. This $\mathrm{C} 4$ acid is transported from $\mathrm{MC}$ to the $\mathrm{BSC}$ chloroplasts where it is decarboxylated by NADP-ME to pyruvate and $\mathrm{CO}_{2}$ is released to Rubisco to carry out the Calvin cycle reactions. In C4 rice, Rubisco should be expressed in BSC and hence the increased $\mathrm{CO}_{2}$ levels at its site will reduce its oxygenation activity subsequently reducing the photorespiration. 3-PGA: 3-Phosphoglycarate, CA: Carbonic anhydrase, DiT1: Dicarboxylate translocator1, DiT2: Dicarboxylate translocator2, MEP: Mesophyll envelope protein, NADP-MDH: NADP-Malate dehydrogenase, NADP-ME: NADP-malic enzyme, PEP: Phosphoeno/pyruvate, OAA: Oxaloacetate, OMT: Oxoglutarate/malate translocator, PEPC:

Phosphoenolpyruvate carboxylase, PPDK: Pyruvate orthophosphate (Pi) dikinase, PPT: Phosphoeno/pyruvate phosphate translocator, Rubisco: Ribulose-1,5-bisphosphate carboxylase/oxygenase, RuBP: Ribulose-1,5-bisphosphate, and TPT: Triose-phosphate phosphate translocator.

carboxylase called phosphoenolpyruvate carboxylase (PEPC, EC 4.1.1.31). The oxaloacetate is then converted to malate or aspartate and is transported to BSCs where it is decarboxylated and the $\mathrm{CO}_{2}$ is released. This $\mathrm{CO}_{2}$ is refixed by Rubisco and all the subsequent activities of Calvin cycle take place in chloroplast of BSCs (Nelson and Langdale 1989). Consequently, to make functioning $\mathrm{C} 4$ rice, Rubisco activity has to be greatly reduced in MCs and increased in BSCs which then confines the Calvin cycle to the BSCs of rice, like in a $\mathrm{C} 4$ system. On the other hand, certain genes encoding the C4 enzymes such as $\beta$ carbonic anhydrase (CA) and PEPC have to be over expressed in cytosol of MCs of rice in order to facilitate the primary $\mathrm{CO}_{2}$ fixation so that $\mathrm{CO}_{2}$ can be concentrated and supplied to Rubisco in the BSCs. The C4 cycle also involves extensive transport of metabolites across the chloroplast envelope membrane and plasmalemma of MC and BSC (Figure 3). As such, in addition to the core $\mathrm{C} 4$ enzymes namely $\mathrm{CA}, \mathrm{PEPC}$, pyruvate orthophosphate $(\mathrm{Pi})$ dikinase (PPDK, EC 2.7.9.1), NADPdependent malate dehydrogenase (NADP-MDH, EC 1.1.1.82) and NADP-dependent malic enzyme (NADP$\mathrm{ME}$, EC 1.1.1.40), C4 pathway also requires insertion of metabolite transporters for oxaloacetate, malate, triosephosphate and pyruvate into rice to provide increased transport capacity for the $\mathrm{C} 4$ cycle intermediates so that the Calvin cycle can function effectively in the BSCs (Weber and von Caemmerer 2010).
The photorespiration in mesophyll cells has to be greatly reduced

In C3 plants carbon fixation and Calvin cycle take place in MCs. During carbon fixation, ribulose- 1, 5- bisphosphate (RuBP) - a five carbon compound, catalyzed by an enzyme ribulose-1,5-bisphosphate carboxylase oxygenase (Rubisco, EC.4.1.1.39) reacts with $\mathrm{CO}_{2}$ to form two molecules of 3-carbon compound called the 3phosphoglycerate (3-PGA). Within the Calvin cycle, the two PGA molecules form an energy rich molecule of sugar (triose phosphate) and regenerates RuBP for the next cycle. At current atmospheric $\mathrm{CO}_{2}$ concentrations (ca. $400 \mathrm{ppm}$ ) Rubisco also catalyses a reaction between $\mathrm{RuBP}$ and $\mathrm{O}_{2}$ resulting in one molecule each of 2phosphoglycolate and 3-PGA (Peterhansel and Maurino 2011). The 2-phosphoglycolate has to be converted back to 3-PGA through the process called photorespiration, which involves a series of biochemical reactions. During this process a loss of previously fixed carbon and nitrogen occurs and extra energy must also be used (Sharpe and Offermann 2013).

C4 plants have developed mechanisms to restrict localization and activities of Rubisco in BSCs. MCs spatially prevent the contact between Rubisco in BSCs and $\mathrm{O}_{2}$ in the intercellular spaces, thus preventing loss of energy through photorespiration. The elimination of photorespiration by $\mathrm{C} 4$ plants is evidenced by their very low $\mathrm{CO}_{2}$ compensation point which is nearly zero and 


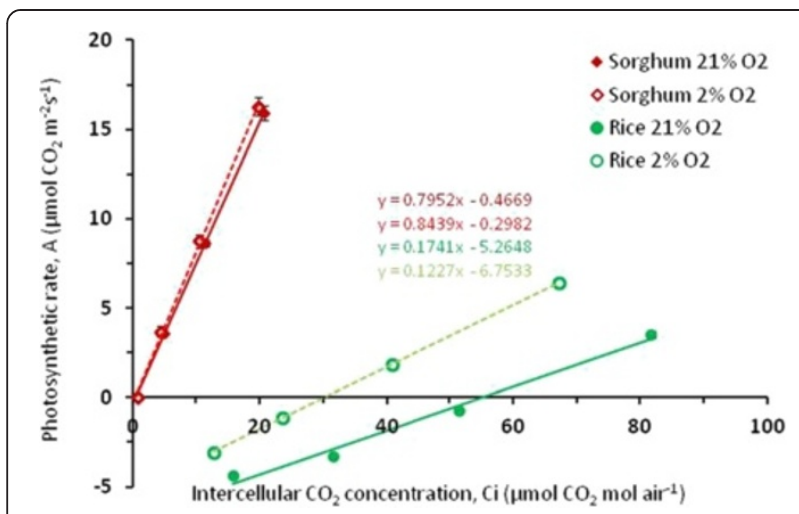

Figure 4 Rate of photosynthesis in $\mathrm{C} 3$ and $\mathrm{C} 4$ at two different ( $21 \%$ and $2 \%$ ) $\mathrm{O}_{2}$ levels. The rate of photosynthesis or the $\mathrm{CO}_{2}$ assimilation rate $(\mathrm{A})$ was measured at intercellular $\mathrm{CO}_{2}$ concentration of $0,20,50,100$ and $200 \mathrm{mmol} \mathrm{mol}^{-1}$ altered at an interval of three minutes. The temperature of the block and the leaf was $28 \pm 1^{\circ} \mathrm{C}$, relative humidity was maintained at $68 \pm 5 \%$, constant light intensity of $1500 \mu \mathrm{mol} \mathrm{m} \mathrm{m}^{-2}$ and the flow rate was maintained at $400 \mathrm{mmol} \mathrm{s}^{-1}$

constantly high carboxylation efficiency (CE) without responding to the changes in $\mathrm{O}_{2}$ concentrations (Figure 4). In contrast, in $\mathrm{C} 3$ plants, with the change in $\mathrm{O}_{2}$ concentration from $21 \%$ to $2 \%$, the compensation point significantly decreased from 55 to $30 \mathrm{ppm}$ (Table 1). In Figure 4, the CE was calculated according to (Li et al. 2009) which showed that $\mathrm{CE}$ of sorghum did not significantly change with the change in $\mathrm{O}_{2}$ level, but in rice there was a highly significant improvement in $\mathrm{CE}$ when the level of $\mathrm{O}_{2}$ was decreased from 21 to $2 \%$ (Figure 4 and Table 1). The increase in $\mathrm{CE}$ in sorghum was just $6.1 \%$ while that in rice was $41.5 \%$ with the decrease in intercellular $\mathrm{O}_{2}$ concentration to $2 \%$ (Table 1). These data show that, there is a great potential to increase the photosynthetic capacity of rice by decreasing the photorespiration which in turn would increase the yield substantially. One way to reduce photorespiration in $\mathrm{MC}$ is by reducing the glycine decarboxylase (GDC) protein in $\mathrm{MC}$ and restrict its accumulation in $\mathrm{BSC}$ so that the decarboxylation of glycine occurs exclusively in BSC, thereby generating higher $\mathrm{CO}_{2}$ concentration in BSC, similar to that in C3-C4 intermediates (Monson and Rawsthorne 2000). The $\mathrm{C} 4$ rice consortium is testing this approach by using artificial microRNA designed against rice GDC-H subunit which is driven by $Z m P E P C$ promoter (Kajala et al. 2011). Such a biochemical mechanism requires cellular specialization of the BSCs which include an increase in chloroplast numbers and mitochondria enriching the organelle content of the rice BSCs to help in recapture of the $\mathrm{CO}_{2}$ released by the decarboxylation of glycine by GDC (Ueno 2011). Another approach that was successful to capture the $\mathrm{CO}_{2}$ released by photorespiration to the site of photosynthesis is by transfer of Escherichia coli glycolate catabolic pathway to chloroplasts of Arabidopsis thaliana in which glycolate in chloroplast was directly converted to glycerate (Kebeish et al. 2007). This strategy which reduced photorespiration and enhanced photosynthesis in Arabidopsis involved stepwise nuclear transformation with five chloroplast targeted bacterial genes encoding glycolate dehydrogenase, glyoxylate carboligase and tartronic semialdehyde reductase could be applied to other C3 plants such as rice, however, the use of bacterial genes may not be preferred in engineering of $\mathrm{C} 4$ rice.

\section{Engineering of C4 pathway into rice}

It was thought that single cell $\mathrm{C} 4$ system could be faster to install in $\mathrm{C} 3$ plants. There are attempts to engineer single cell C4 photosynthesis system in rice too (Miyao et al. 2011). To introduce single cell C4-like pathway in which $\mathrm{MC}$ is made to capture and release $\mathrm{CO}_{2}$ in the manner it takes place in Hydrilla verticillata (L.f) Royle., four enzymes (PEPC, PPDK, NADP-MDH, and NADP$\mathrm{ME}$ ) involved in the pathway were overproduced in the transgenic rice leaves ( $\mathrm{Ku}$ et al. 1999; Fukayama et al. 2001; Tsuchida et al. 2001; Taniguchi et al. 2008). A few of the major problems encountered that need to be addressed to make a single-cell C4-like pathway in rice are: mechanism to facilitate transport activity of PEP across the chloroplast envelope, the import of OAA into the chloroplasts and the direction of the NADP-ME reaction, involvement of $\mathrm{NADP}-\mathrm{MDH}$, the presence of endogenous PEPC inside the MC chloroplast of rice and further elevation of NADP-MDH activity were reported to be necessary (Miyao et al. 2011). Terrestrial single cell C4 species such as Bienertia cycloptera, B. sinuspersici and Suaeda aralocaspica, belonging to Chenopodiaceae family also need spatial compartmentalization of the carbon assimilation and decarboxylation (Chuong et al.

Table 1 Differences in carboxylation efficiency (CE) and $\mathrm{CO}_{2}$ compensation point (CP) between rice (C3) and sorghum (C4) at 21 and $2 \%$ oxygen level

\begin{tabular}{|c|c|c|c|c|c|}
\hline & \multicolumn{2}{|c|}{$\mathrm{CE}\left(\mathrm{mol} \mathrm{mol}{ }^{-1}\right)$} & \multirow{2}{*}{$\begin{array}{l}\text { Increase in CE when } \mathrm{O}_{2} \text { level was reduced from } 21 \text { to } 2 \% \\
\text { (\%) }\end{array}$} & \multicolumn{2}{|c|}{$\mathrm{CO}_{2} \mathrm{CP}\left(\mathrm{mol} \mathrm{mol}^{-1}\right)$} \\
\hline & $21 \% \mathrm{O}_{2}$ & $2 \% \mathrm{O}_{2}$ & & $21 \% \mathrm{O}_{2}$ & $2 \% \mathrm{O}_{2}$ \\
\hline Rice & 0.123 & 0.174 & 41.5 & 54.877 & 30.241 \\
\hline Sorghum & 0.795 & 0.844 & 6.1 & 0.587 & 0.365 \\
\hline
\end{tabular}


2006). These species have dimorphic chloroplasts in those compartments. The earlier attempts produced futile cycle which was due to no change in anatomy, lack of appropriate transporters and the maize genes transformed into rice were not appropriately expressed in cell specific manner and were not regulated like in maize but were regulated like the endogenous rice C3 isoforms (Miyao et al. 2011).

To engineer the photosynthetic pathway from C3 to $\mathrm{C} 4$ within two decades, which took million of years in nature, $\mathrm{C} 4$ rice consortium began the simultaneous gene discovery and engineering of already known genes into rice aiming to form $\mathrm{C} 4$ rice with Kranz type anatomy. C4 genes such as CA, PEPC, PPDK, NADP-ME, and $N A D P-M D H$ are cloned from maize and transformed into rice. Also the transporters that were over expressed in the C4 metabolic pathways such as 2-oxoglutarate /malate transporter (OMT1), dicarboxylate transporter1 (DiT1), dicarboxylate transporter2 (DiT2), PEP/phosphate transporter (PPT1), mesophyll envelope protein (MEP) and triose-phosphate phosphate translocator (TPT) that were recently identified through proteomics of maize BS and MS cells (Friso et al. 2010) are being transformed into rice (Figure 3 ). The $\mathrm{C} 4$ rice consortium members are also involved in discovering novel genes related to Kranz anatomy (Wang et al. 2013b). Once tested, the promising candidate genes controlling the Kranz anatomy will also be introduced in the rice plants that have been engineered with the $\mathrm{C} 4$ biochemical pathway genes.

\section{Conclusion}

The C4 photosynthetic pathway has evolved more than 66 times in different species, suggesting that C3 plants may be in some way preconditioned to $\mathrm{C} 4$ photosynthesis. Developing crop plants with enhanced photosynthesis will improve crop yield and make efficient use of resources in a sustainable manner. The $\mathrm{C} 4$ rice consortium is striving to install a maize-like photosynthetic mechanism in rice to break its yield barrier and to breed a new generation of "climate-ready" rice which will yield more even under the situations of increasing temperature and decreasing water availability. This initiative demands a holistic approach of understanding the regulatory networks and the complex mechanism underlying the $\mathrm{C} 4$ photosynthetic pathway and their systematic introduction into the rice genome.

Competing interests

The authors declare that they have no competing interests.

\section{Authors' contributions}

SK conceptualized the study and prepared the manuscript. GR designed experiment for gas exchange and leaf anatomy, analyzed data and contributed in preparation of the manuscript. WPQ supervised SK and GR and revised the manuscript. All authors read and approved the final manuscript.

\section{Acknowledgements}

We are grateful to Joan Salonga and Glenn Dimayuga for gas exchange measurements, Abigail Elmido-Mabilangan for microscopy and other staff of C4 Rice Center, International Rice Research Institute (IRRI) for their technical support. This study under the C4 Rice Center at IRRI was supported by Bill and Melinda Gates Foundation and UKAID.

\section{Author details}

${ }^{1}$ C4 Rice Center, International Rice Research Institute, Los Banos, Laguna, Philippines. ${ }^{2}$ Department of Animal and Plant Sciences, University of Sheffield, Sheffield, UK.

Received: 9 May 2013 Accepted: 12 September 2013

Published: 28 October 2013

\section{References}

Akita S (1994) Eco-physiological aspect of raising the yield plateau of irrigated rice in the tropics. In: Cassman KG (ed) Breaking the yield barrier, Proceedings of a workshop on rice yield potential in favorable environments, IRRI, 29 November - 4 December 1993. International Rice Research Institute, Philippines

Chuong SDX, Franceschi VR, Edwards GE (2006) The cytoskeleton maintains organelle partitioning required for single-cell C4 photosynthesis in Chenopodiaceae species. Plant Cell 18:2207-2223

Dengler NG, Nelson T (1999) Leaf structure and development in C4 plants. In: Sage RF, Monson RK (eds) C4 plant biology. Academic Press, San Diego, California, pp 133-172

Douce R, Heldt HW (2000) Photorespiration. In: Leegood RC, Sharkey TD, von Caemmerer S (eds) Photosynthesis: Physiology and metabolism. Kluwer Academic, Dordrecht, The Netherlands, pp 115-136

Ehleringer JR, Monson RK (1993) Evolutionary and ecological aspects of photosynthetic pathway variation. Annu Rev Ecol Syst 24:411-439

FAO (2009) FAO's Director-General on how to feed the World in 2050. Popul Dev Rev 35:837-839, doi: 10.1111/j.1728-4457.2009.00312.x

Friso G, Majeran W, Huang MS, Sun Q, van Wijk KJ (2010) Reconstruction of metabolic pathways, protein expression, and homeostasis machineries across maize bundle sheath and mesophyll chloroplasts: large-scale quantitive proteomics using the first maize genome assembly. Plant Physiol 152:1219-1250

Fukayama H, Tsuchida H, Agarie S, Nomura M, Onodera H, Ono K, Lee BH, Hirose S, Toki S, Ku MSB, Makino A, Matsuoka M, Miyao M (2001) Significant accumulation of C4-specific Pyruvate, orthophosphate dikinase in a C3 plant, rice. Plant Physiol 127:1136-1146

Hibberd JM, Sheehy JE, Langdale JA (2008) Using C4 photosynthesis to increase the yield of rice- rationale and feasibility. Curr Opin Plant Biol 11:228-231

Kajala K, Covshoff S, Karki S, Woodfield H, Tolley BJ, Dionora MJ, Mogul RT, Mabilangan AE, Danila FR, Hibberd JM, Quick WP (2011) Strategies for engineering a two-celled C4 photosynthetic pathway into rice. J Exp Bot 62:3001-3010

Kebeish R, Niessen M, Thiruveedhi K, Bari R, Hirsch HJ, Rosenkranz R, Stabler N, Schonfeld B, Kreuzaler F, Peterhansel C (2007) Chloroplastic photorespiratory bypass increases photosynthesis and biomass production in Arabidopsis thaliana. Nat Biotechnol 25:593-599, doi: 10.1038/nbt1299

Kim GT, Tsukaya H, Uchimiya H (1998) The CURLY LEAF gene controls both division and elongation of cells during the expansion of the leaf blade in Arabidopsis thaliana. Planta 206:175-183

Ku MSB, Agarie S, Nomura M, Fukayama H, Tsuchida H, Ono K, Hirose S, Toki S, Miyao M, Matsuoka M (1999) High-level expression of maize phosphoeno/pyruvate carboxylase in transgenic rice plants. Nat Biotechnol 17:76-80

Kubien DS, Whitney SM, Moore PV, Jesson LK (2008) The biochemistry of Rubisco in Flaveria. J Exp Bot 59:1767-1777

Leegood RC (2008) Roles of the bundle sheath cells in leaves of C3 plants. J Exp Bot 59:1663-1673

Li Y, Gao Y, Xu X, Shen Q, Guo S (2009) Light saturated photosynthetic rate in high-nitrogen rice (Oryza sativa L.) leaves is related to chloroplast $\mathrm{CO}_{2}$ concentration. J Exp Bot 60:2531-2360

Matsuoka M, Kyozuka J, Shimamoto K, Kano-Murakami Y (1994) The promoters of two carboxylases in a C4 plant (maize) direct cell-specific, light regulated expression in a C3 plant (rice). Plant J 6:311-319 
Miyao M, Masumoto C, Miyazawa SI, Fukayama H (2011) Lessons from engineering a single-celled C4 photosynthetic pathway into rice. J Exp Bot 62:3021-3029

Monson RK, Rawsthorne S (2000) $\mathrm{CO}_{2}$ assimilation in C3-C4 intermediate plants. In: Leegood RC, Sharkey TD, von Caemmerer S (eds) Photosynthesis: physiology and metabolism. Kluwer Academic Publishers, Dordrecht, The Netherlands, pp 533-550

Muhaidat R, Sage RF, Dengler NG (2007) Diversity of Kranz anatomy and biochemistry in C4 eudicots. Am J Bot 94:362-381

Nelson T, Langdale JA (1989) Patterns of leaf development in C4 plants. Plant Cell 1:3-13

Nikolopoulos D, Liakopoulos G, Drossopoulos I, Karabourniotis G (2002) The relationship between anatomy and photosynthetic performance of heterobaric leaves. Plant Physiol 129:235-243

Nomura M, Higuchi T, Ishida Y, Ohta S, Komari T, Imaizumi N, Miyao-Tokutomi M, Matsuoka M, Tajima S (2005) Differential expression pattern of C4 bundle sheath expression genes in rice, a C3 plant. Plant Cell Physiol 46:754-761

Peterhansel C, Maurino VG (2011) Photorespiration redesigned. Plant Physiol 155:49-55

Rizal G, Karki S, Thakur V, Chatterjee J, Coe RA, Wanchana S, Quick WP (2012) Towards a C4 rice. Asian J Cell Biol 7:13-31

Robles P, Fleury D, Candela H, Cnops G, Alonso-Peral MM, Anami S, Falcone A, Caldana C, Willmitzer L, Ponce MR, Van Lijsebettens M, Micol JL (2010) The RON1/FRY1/SAL1 gene is required for leaf morphogenesis and venation patterning in Arabidopsis. Plant Physiol 152:1357-1372

Rossini L, Cribb L, Martin DJ, Langdale JA (2001) The maize Golden2 gene defines a novel class of transcriptional regulators in plants. Plant Cell 13:1231-1244

Sage RF (2004) The evolution of C4 photosynthesis. New Phytol 1618:341-370

Sage RF, Sage TL, Kocacinar F (2012) Photorespiration and the evolution of C4 photosynthesis. Annu Rev Plant Biol 63:19-47

Sharpe RM, Offermann S (2013) One decade after the discovery of single-cell C4 species in terrestrial plants: what did we learn about the minimal requirement of C4 photosynthesis? Photosynth Res, doi: 10.1007/s1120-0139810-9

Slewinski TL, Anderson AA, Zhang C, Turgeon R (2012) Scarecrow plays a role in establishing Kranz anatomy in maize leaves. Plant Cell Physiol 53:2030-2037, doi: 10.1093/pcp/pcs147

Taniguchi Y, Ohkawa H, Masumoto C, Fukuda T, Tamai T, Lee K, Sudoh S, Tsuchida H, Sasaki H, Fukayama H, Miyao M (2008) Overproduction of C4 photosynthetic enzymes in transgenic rice plants: an approach to introduce the C4-like photosynthetic pathway into rice. J Exp Bot 59:1799-1809

Tolley BJ, Sage TL, Langdale JA, Hibberd JM (2012) Individual maize chromosomes in the C3 plant oat can increase bundle sheath cell size and vein density. Plant Physiol 159:1418-1427

Tsuchida H, Tamai T, Fukayama H, Agarie S, Nomura M, Onodera H, Ono K, Nishizawa Y, Lee BH, Hirose S, Toki S, Ku MS, Matsuoka M, Miyao M (2001) High level expression of C4-specific NADP-malic enzyme in leaves and impairment of photoautotrophic growth in a C3 plant, rice. Plant Cell Physiol 42:138-145

Tsukaya H, Naito S, Redei GP, Komeda Y (1993) A new class of mutations in Arabidopsis thaliana, acaulis1, affecting the development of both inflorescences and leaves. Development 118:751-764

Ueno O (2011) Structural and biochemical characterization of the C3-C4 intermediate Brassica gravinae and relatives, with particular reference to cellular distribution of Rubisco. J Exp Bot 62:5347-5355

Wang P, Fouracre J, Kelly S, Karki S, Gowik U, Aubry S, Shaw MK, Westhoff P, Slamet-Loedin IH, Quick WP, Hibberd JM, Langdale JA (2013a) Evolution of GOLDEN2-LIKE gene function in C3 and C4 plants. Planta 237:481-495

Wang P, Kelly S, Fouracre JP, Langdale JA (2013b) Genome-wide transcript analysis of early maize leaf development reveals gene cohorts associated with the differentiation of C4 Kranz anatomy. Plant J 75:656-670

Waters MT, Moylan EC, Langdale JA (2008) GLK transcription factors regulate chloroplast development in a cell-autonomous manner. Plant J 56:432-444

Waters MT, Wang P, Korkaric M, Capper RG, Saunders NJ, Langdale JA (2009) GLK transcription factors coordinate expression of the photosynthetic apparatus in Arabidopsis. Plant Cell 21:1109-1128
Weber APM, von Caemmerer S (2010) Plastid transport and metabolism of C3 and C4 plants: comparative analysis and possible biotechnological exploitation. Curr Opin Plant Biol 13:257-265

Yoshimura Y, Kubota F, Ueno O (2004) Structural and biochemical bases of photorespiration in C4 plants: quantification of organelles and glycine decarboxylase. Planta 220:307-317

doi:10.1186/1939-8433-6-28

Cite this article as: Karki et al:: Improvement of photosynthesis in rice (Oryza sativa L.) by inserting the C4 pathway. Rice 2013 6:28.

\section{Submit your manuscript to a SpringerOpen ${ }^{\odot}$ journal and benefit from:}

- Convenient online submission

- Rigorous peer review

- Immediate publication on acceptance

- Open access: articles freely available online

- High visibility within the field

- Retaining the copyright to your article

Submit your next manuscript at $>$ springeropen.com 